\title{
A healthy public administration through healthy organizational practices
}

\author{
Miguel Ángel Mañas-Rodríguez ${ }^{1}$ and Luis Alcaraz-Pardo,** \\ 1 University of Almeria (Spain). \\ 2 Private practice (Spain).
}

\begin{abstract}
Título: Una administración pública saludable a través de prácticas organizacionales saludables.

Resumen: En el presente estudio se muestra una propuesta teórica basada en el modelo de Kopelman, Brief y Guzzo (1990) en la que se ha posicionado al liderazgo transformacional como antecedente del clima organizacional, y al capital psicológico como consecuente de dicho clima. Nuestra propuesta ha sido probada haciendo uso de ecuaciones estructurales en una muestra compuesta por 277 empleados de una Administración pública. El buen ajuste de los datos según los índices de bondad de ajuste revisados, tanto en los análisis confirmatorios para cada variable como del modelo estructural final valida estadísticamente nuestra propuesta teórica, aceptándose las hipótesis de estudio. Se hace de esta manera evidente la necesidad de que la Administración plantee medidas basadas en el liderazgo transformacional a nivel individual, de equipos de trabajo y de organización para fortalecer la consecución de resultados organizacionales positivos a través de un clima organizacional y un capital psicológico positivos.

Palabras clave: clima organizacional; liderazgo; capital psicológico; ecuaciones estructurales; Administración pública.
\end{abstract}

\section{Introduction}

Public sector in Spain accounts for $41 \%$ of the expenditure of Gross Domestic Product and its relevance is higher than that of any other economic sector or organization. The central role of Administration, in both numerical data and development of the country, deserves the concentration of efforts so that its operation is suitable (PwC Spain, 2012). This research started out as an analysis derived from changes in the structure and practices of the institutions in this sector with the aim of checking how management practices affect both climate and psychological capital of employees.

Since the studies carried out by Lewin, Lippitt \& White (1939), whose research on experimentally created social climates can be considered the starting point for the scientific study of climate, a rise concerning its study has become more prominent in recent decades due to its wide significance in organizational outcomes (Salgado, Remeseiro \& Iglesias, 1996).

Psychological climate is based on the descriptions of the work environment perceived by the employees (Schneider, 2000). As logical climate is subject to contextual and social influences, socially constructed and common beliefs can emerge producing a shared sense of meaning of the work context, or organizational climate (Kozlowski \& Klein, 2000). It is necessary to distinguish between psychological climate and organizational climate. The first refers to the individual perception of work environment, that's to say a worker or work environment. On the other hand, organiza-

* Correspondence address [Dirección para correspondencia]:

Luis Alcaraz Pardo. Private practice (Spain). E-mail:

lalcarazpardo@gmail.com
Abstract: In the present study we have proposed a theoretical model based on Kopelman, Brief \& Guzzo's model (1990), in which transformational leadership is positioned as an antecedent of organizational climate, and the psychological capital, as a consequence of that climate. The theoretical model was tested using structural equations in a sample of $277 \mathrm{em}$ ployees of a public Administration. The good fit of the data according to the revised goodness of fit indexes, both in the confirmatory analysis for each variable and in the structural model statistically validates our theoretical model, accepting the study hypotheses. This makes clear the need for the Administration to propose transformational leadership measures at the individual, team and organizational levels to strengthen the achievement of positive outcomes through positives organizational climate and psychological capital.

Key words: organizational climate; leadership; psychological capital; structural equations; public Administration.

tional climate refers to the shared perceptions of employees concerning the practices in a particular setting (Schulte et al. 2009). Employees share similar interpretations of those events that have an influence on their assessment so that the potential difference is such that climate can become key to achieving goals (Ostroff \& Bowen, 2000).

At the same time, that research on organizational climate is constantly increasing, as can be contrasted in the number of search results from Scopus and ProQuest. The focus on the study of climate has been changing from the original investigations to recent times; besides, its conceptualization remains a matter of debate (Moran \& Volkwein, 1992; Schneider, Ehrhart \& Macey, 2013). Early research on climate, including the aforementioned study by Lewin, Lippitt \& White (1939) emphasized the employees' overall perception of their organizations, and this was based on the belief that people create consistent cognitive representations of the total situation (Lewin, 1951). Later, the interest in the study of climate jumps squarely into the field of organizations. Somewhat independently of the author or theory of reference, organizational environment is composed of dimensions of variable number, and these dimensions will characterize specific aspects of the organizational environment (Salgado, Remeseiro \& Iglesias, 1996; Schneider, Ehrhart \& Macey, 2013). This paper based the study of climate on the position of the Competing Value Framework of Quinn \& Rohrbaugh (1983), proposing two main axes around which four dimensions of the variable are linked: the axis "structure," with the ends of "flexibility" versus "control" and the axis "focus" with the ends of "internal orientation" versus "external orientation". The combination of these two axes results in the dimensions of support, innovation, rules and goals. As indicated in Boada i Grau, De Diego Vallejo \& Agulló (2004), 
some dimensions of the resulting spatial model will predominate in the environment of an organization over others. In addition, it is generally unknown whether the pattern of results in research on climate can be generalized to other organizations or institutions, for example to the public sector. When conducting assessments to measure the same variable, different instruments from different theoretical models can be used, and they do not necessarily coincide with the Competing Value Framework of Quinn \& Rohrbaugh (1983) about climate in which this research is based.

As climate is based on descriptive employee's perceptions of human resources practices, among which leadership styles are included (Kopelman, Brief \& Guzzo, 1990), it is justified that the relationship between leadership and climate has been widely studied in organizational literature. The notion of leadership as a climate antecedent has hardly changed over the past five decades (Zohar \& Tenne-Gazit, 2008) and plenty of studies have shown a direct correlation between leadership and organizational results. For example, according to Bass \& Avolio (2000), transformational leadership style would rather enhance the development of organizational results than a style based on transactional leadership, which is based on the satisfaction or fulfillment of a contractual obligation by both parties. Transformational leadership refers to the leader moving the employees through attitudes, beliefs and values; achieving a performance above expectations (Bass, 1985). The fundamental difference is that the transformational leader knows how to lead others towards a goal that ends up being perceived as shared and achieves the group and organization commitment (Salanova, 2008). On the other hand, in the study conducted by Zohar \& Tenne-
Gazit (2008) it was shown, with a sample of 1328 soldiers, that transformational leadership predicts the emergence and subsequent strength of climate, both in a direct relationship and in a relationship mediated through the creation of social networks between members of the groups. In general, behaviors that correspond with transformational leadership are those that transmit an attractive view; serve as role models for employees; and respond to individual values, needs and goals training employees and strengthening a climate of trust (Syrek, Apostel \& Antoni, 2013). Our paper takes the theoretical proposition by Rafferty \& Griffin (2004), which is based on the model of Bass (1985) for transformational leadership. In a different way from previous studies, our sample consists of employees of a public administration and the relationships will be tested in a structural model (Rosseel, 2012a). Thus, we propose our first hypothesis:

H1: Transformational leadership is positively and significantly related to organizational climate.

We have positioned transformational leadership as an antecedent of organizational climate (see Figure I), and we have checked this relationship with psychological capital of employees as a consequence of such climate. This structure follows the model of Kopelman, Brief \& Guzzo (1990). According to which, organizational culture influences management practices of Human Resources in the organizations, among which are leadership practices. These, as a whole, influence organizational climate and, finally, productivity (Bowen \& Ostroff, 2004). Therefore, practices such as transformational leadership influence productivity through its effects on climate (Mañas, González-Romá \& Peiró, 1999).

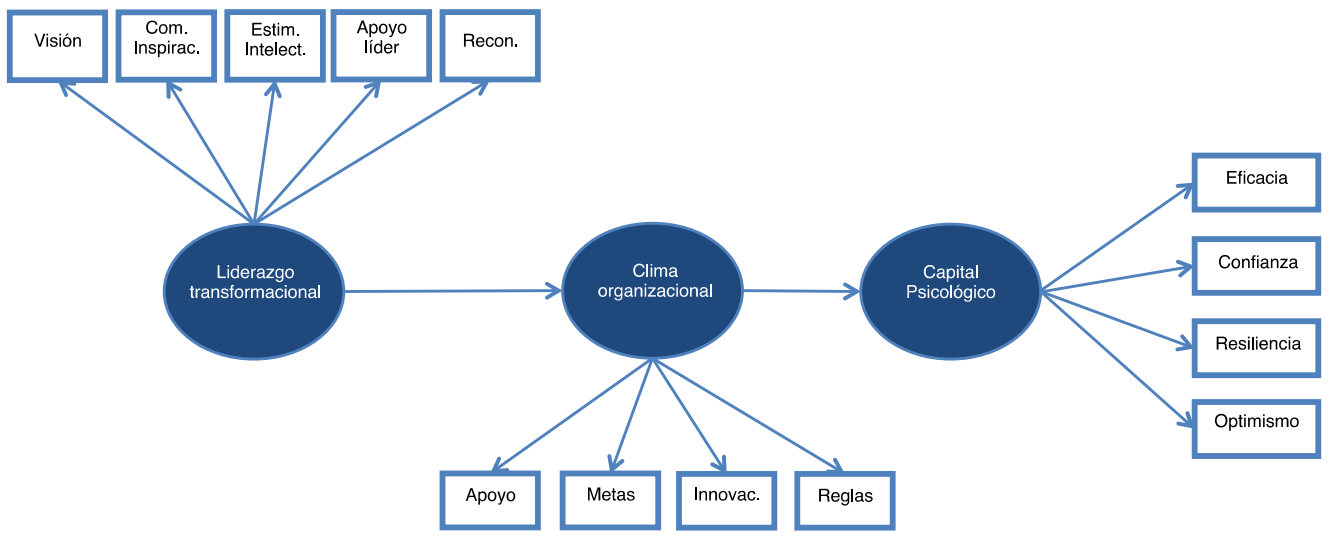

Figure I. Theoretical model proposed for study.

Climate also plays an important role in the attitudes of workers. For a little more than a decade, the relationship between climate and attitudes, such as job satisfaction, commitment and even turnover intentions, have been demonstrated (Carr, Schmidt, Ford \& DeShon, 2003). Psychological capital, attitudinal component of our theoretical proposal, has its starting point in the studies of Luthans \& Youssef (2004), and is defined as the positive appraisal of circum- stances and probability for success based on motivated effort and perseverance. At the same time, a positive psychological capital has been linked to positive outcomes. Using a sample of 79 police leaders and 264 subordinates, Walumbwa, Peterson, Avolio \& Hartnell (2010) found that leader's psychological capital was positively related to the performance of the subordinates and with this relationship mediated by climate relationship, in such a way that the relationship was stronger 
when service climate was perceived to be high versus low. Furthermore, psychological capital predicted nominal performance. One explanation given is that leaders are described by their followers as role models; thus, when they perceive that leader's behavior is positive, they behave similarly in an attempt to emulate their ways so that the psychological capital of the leader would positively influence the psychological capital of employees (Walumbwa et al., 2010). In another research, Luthans, Avolio, Avey \& Norman (2007) analyzed the four dimensions of psychological capital that we stand in the present work: efficacy, hope, resilience and optimism and they found a significant positive relationship between these and performance and satisfaction. The grouping of these four dimensions into one, psychological capital, is congruent as it predicts better variables, such as performance and satisfaction, than these four dimensions taken individually. Currently, there are studies that indicate that psychological capital is related to attitudes, behaviors and performance in organizations; and that performance can be improved to develop psychological capital of employees (Luthans, Avey, Avolio \& Peterson, 2010; Luthans, Luthans \& Luthans, 2004). As our second hypothesis we have checked the relationship between organizational climate and psychological capital, composed of the four dimensions resulting from the study by Luthans et al. (2007). It will be tested an influence relationship between the two variables object of study rather than a mediating relationship of psychological capital, as studied in the aforementioned research by Walumbwa et al. (2010). Thus, understanding the psychological capital and its component dimensions in accordance with the proposal of Luthans \& Youssef (2004), we propose the second hypothesis of this research:

H2: Organizational climate has a positive and significant relationship with psychological capital.

In order to position the present study in the literature about organizations, it should be noted that the proposed relationship between climate and psychological capital has not been previously studied, and that is based on a sample of public employees and integrates a variable on practices of human resources management, transformational leadership. On this variable will be viable intervention if the structural equation modeling is adjusted to the goodness of fit indices to revise. Today, most of the research conducted has explored the mediation role of psychological capital in the relationship between climate and organizational results, as Organizational Citizenship Behavior (Suifan, 2016; Qadeer \& Jaffery, 2014; Luthans, Norman, Avolio \& Avey, 2014). However, the direction of this relationship still remains ambiguous and psychological capital has not been fully studied as a mediating mechanism in research literature (Qadeer \& Jaffery, 2014). Instead, we will test other proposal based on Kopelman, Brief \& Guzzo’s model (1990).

\section{Method}

\section{Participants}

Participants in this study were 277 employees from a public Administration in the province of Almería. Regarding age, the most represented group of participants, $64.4 \%$, was between 35 and 50 years. According to sex, men comprised $45.5 \%$, while women comprised $54.5 \%$ of the sample. The most representative academic level was college degree, with $69.8 \%$, followed by vocational training, with $18.7 \%$ of the total.

\section{Instruments}

Each variable was measured by administering a questionnaire. In the case of organizational climate, FOCUS-93 questionnaire was applied in its 12-item version, with 3 items for each dimension (support, goals, innovation and rules). This questionnaire, which was originally developed by Van Muijen et al. (1999), is based on the Competing Value Framework by Quinn \& Rohrbraugh (1983). All the items are on 7-point Likert scale, ranging from 1 (strongly disagree) to 7 (strongly agree). For the transformational leadership variable, the questionnaire by Rafferty and Griffin (2004), based on the Bass model (1985), was used after review. The instrument consists of 15 items, with 3 items for each dimension (vision, inspirational communication, intellectual stimulation, supportive leadership and personal recognition). All the items are on 7 -point Likert scale, ranging from 1 (strongly disagree) to 7 (strongly agree). Finally, the psychological capital variable was measured by the instrument developed by Luthans et al. (2007) in its reduced version of 12 items. All items use a 6-point Likert scale response format, with answers ranging from 1 (strongly disagree) to 6 (strongly agree), with 2 or 3 items for each dimension (efficacy, hope, resiliency and optimism).

\section{Procedure}

The questionnaires were applied to each employee considering the working groups of the administration, respecting their working day, and on the premises of the institution itself. Instructions required for the completion of the instruments were given previously and all doubts were resolved individually. Confidentiality and anonymity in information processing was guaranteed by the use of codes in the questionnaires. The information was treated by creating a database on IBM SPSS program, version 22. Subsequently, the base was exported to R, version 1.65, for structural equation modeling (Fox, 2006), to which the following packages were installed: "Lavaan" version 0.5-16 (Rosseel, 2012b), "e1071" for studying the univariate normal, "MVN" package for multivariate normality, "foreign" for reading data from SPSS and "qgraph" and "semPlot" packages for graphic models. Using $\mathrm{R}$, the proposed theoretical model will be determined and 
validated so that if our model produces a covariance matrix of the population that is consistent with the observed matrix covariance, our theoretical model will be validated (Rosseel, 2014).

Confirmatory factor analysis (CFA) models were applied, after exploring the data in SPSS software, on the bases of the criteria for fitting the models suggested by $\mathrm{Hu} \&$ Bentler (1999). The models were adjusted using Diagonally Weighted Least Squares (DWLS) or Robust Maximum Likelihood (RML), depending on the fitted model (Chou, Bentler \& Satorra, 1991; Jöreskog \& Sörbom, 1996). In particular, since DWLS method requires a great amount of data in order to be applicable: number of data need for parameters to be estimated is approximately $p(p+1) / 2$, the RML method was used when the amount of parameters to be estimated in the model were so large that the DWLS method could not be applied (Hox, Maas \& Brinkhuis, 2010). Standardized values were taken for both latent and observed variables, what is called "completely standardized solution" (Rosseel, 2012a). In addition, in order to measure the internal consistency of the dimensions the Cronbach's alpha was obtained for each of the constructs (Cronbach, 1951).

\section{Results}

Table 1 summarizes the results of goodness of fit index for each variable. The normality assumption was not met for any of the variables. In the case of organizational climate, the estimation method used was MLR (see Figure 2).

Table 1. Summary of goodness of fit indices for each model.

\begin{tabular}{|c|c|c|c|c|c|c|}
\hline Model & CFI & TLI & RMSEA & LO90* & HI90* & SRMR \\
\hline Organizational climate & 0,972 & 0,962 & 0,052 & 0,036 & 0,068 & 0,035 \\
\hline Transformational leadership & 0,958 & 0,945 & 0,075 & 0,063 & 0,087 & 0,036 \\
\hline Psychological capital & 0,988 & 0,984 & 0,037 & 0,008 & 0,058 & 0,065 \\
\hline Final SEM & 0,996 & 0,995 & 0,023 & 0 & 0,044 & 0,059 \\
\hline
\end{tabular}

*LO90 = Lower limit of a $90 \%$ confidence interval for RMSEA index, and HI90 = Upper limit of a $90 \%$ confidence interval for the same index.

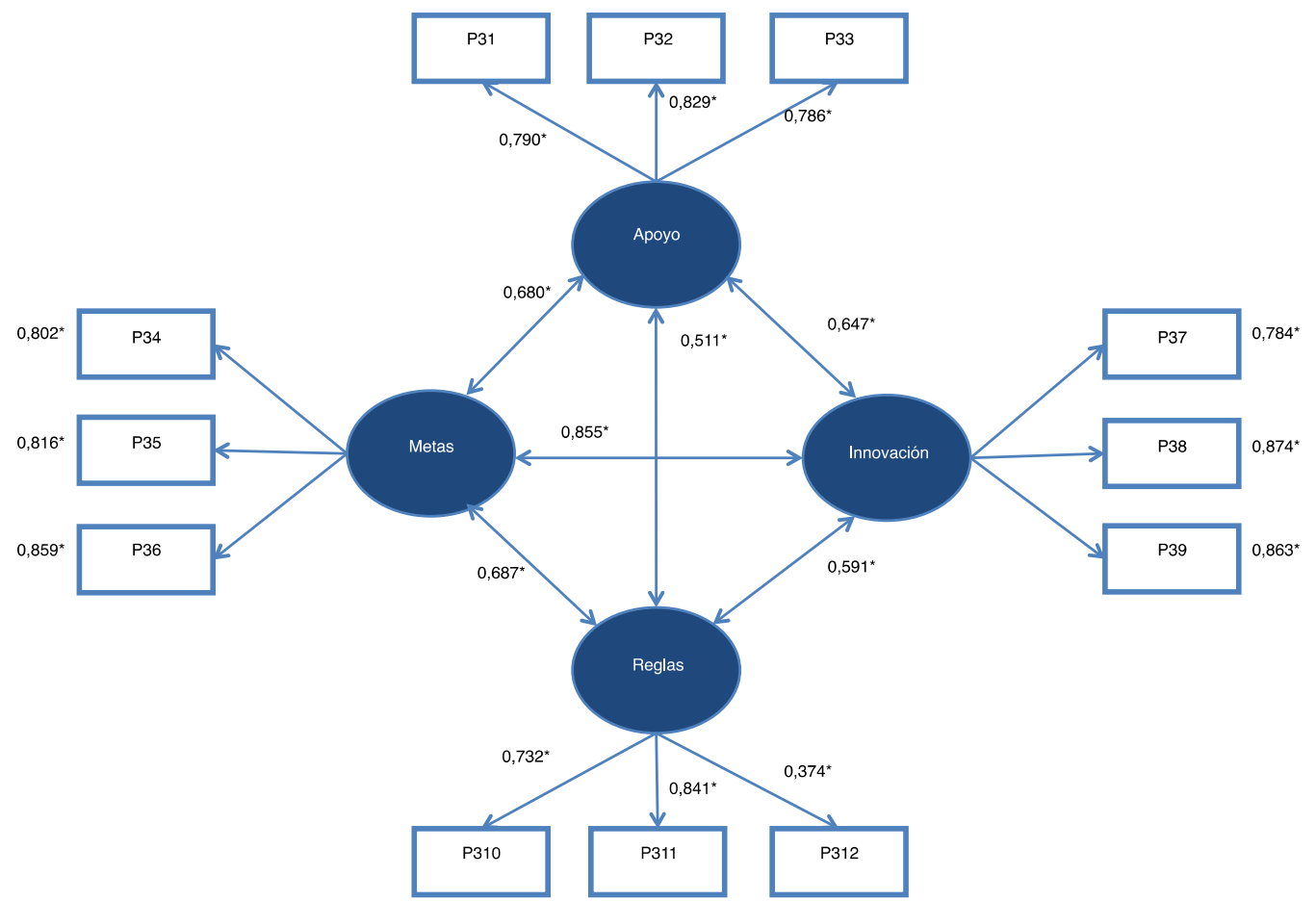

Figure 2. Confirmatory model of organizational climate, estimated using the MLR method. *p-value $<0,01$.

Based on the relative fit indices (Comparative Fit Index) $=0.972$ and TLI (Tucker Lewis Index) $=0.962$, we obtain a good data adjustment; both indices can lead to a result between 0 and 1, with 0 indicating a poor fit and 1 a perfect fit, considering good those results above 0.9 ( Hu \& Bentler, 1999). The results of the indices of absolute fit, RMSEA
(Root Mean Square Error of Approximation) $=0.052(90 \%$ confidence interval with lower and upper limit of 0.036 and 0.068 , respectively) and SRMR (Standardized Root Mean Residual $)=0.035$, indicated a good data fit. Scores below 0.08 in both indices indicate a correct fitting model (Hu \& Bentler, 1999). 
In the confirmatory analysis for the transformational leadership variable (see Figure 3), the estimation method was again MLR. The fit of the data was based, as in the previous variable, on relative and absolute fit indices, $\mathrm{CFI}=0.958$;
TLI $=0.945 ;$ RMSEA $=0.075(90 \%$ confidence interval with lower and upper limit of 0.063 and 0.087 , respectively) and $\mathrm{SRMR}=0.036$. Table 2 shows the covariance matrix of the confirmatory model for transformational leadership.

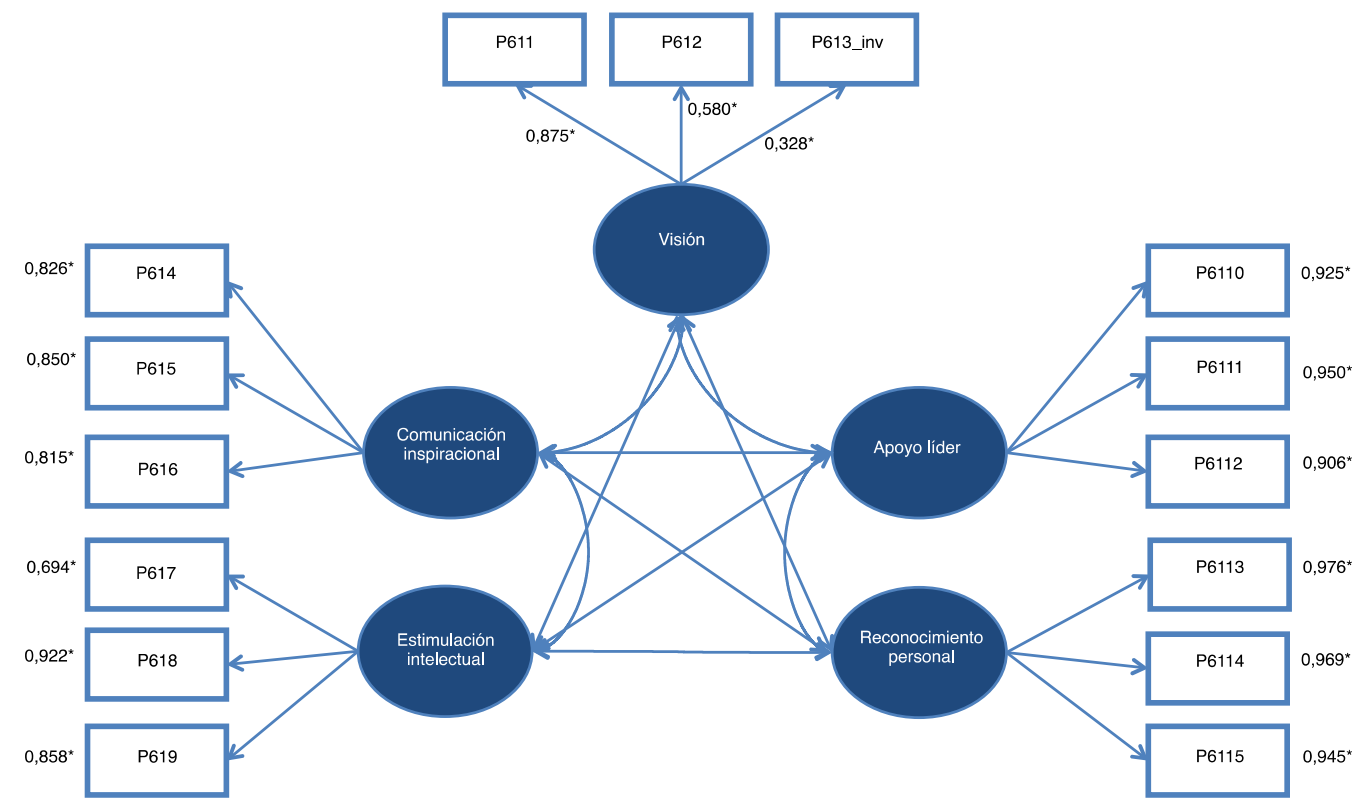

Figure 3. Confirmatory model of transformational leadership, estimated using the MLR method. See Table II for checking the values of the missing covariance estimates. ${ }^{*} p<.01$.

Table 2. Covariance matrix of the confirmatory model of transformational leadership.

\begin{tabular}{lcccc}
\hline Dimensions & 1 & 2 & 3 & 4 \\
\hline 1. Vision & 1 & & & \\
2. Inspirational comm. & $.848^{*}$ & 1 & & \\
3. Intellectual stimul. & $.838^{*}$ & $.852^{*}$ & 1 & 1 \\
4. Supportive leadership & $.833^{*}$ & $.791^{*}$ & $.793^{*}$ & $.877^{*}$ \\
5. Personal recognition & $.729^{*}$ & $.723^{*}$ & $.738^{*}$ & 1 \\
\hline${ }^{*}<.01$ & & & &
\end{tabular}

DWLS estimation method was chosen for confirmatory analysis of the psychological capital variable (see Figure 4). We worked again on the same indices we used to test the fit: $\mathrm{CFI}=0.988 ;$ TLI $=0.984 ;$ RMSEA $=0.037(90 \%$ confidence interval with lower and upper limit of 0.008 and 0.058 , respectively) and SRMR $=0.065$. In this way, the fit of the data was good. In addition to the fit indices, the reliability was calculated using Cronbach's alpha coefficient for each of the confirmatory models (Cronbach, 1951). In the case of organizational climate, a score of 0.907 was obtained, it increased to 0.938 for the transformational leadership variable, and it was 0.853 in the case of the psychological capital variable. 


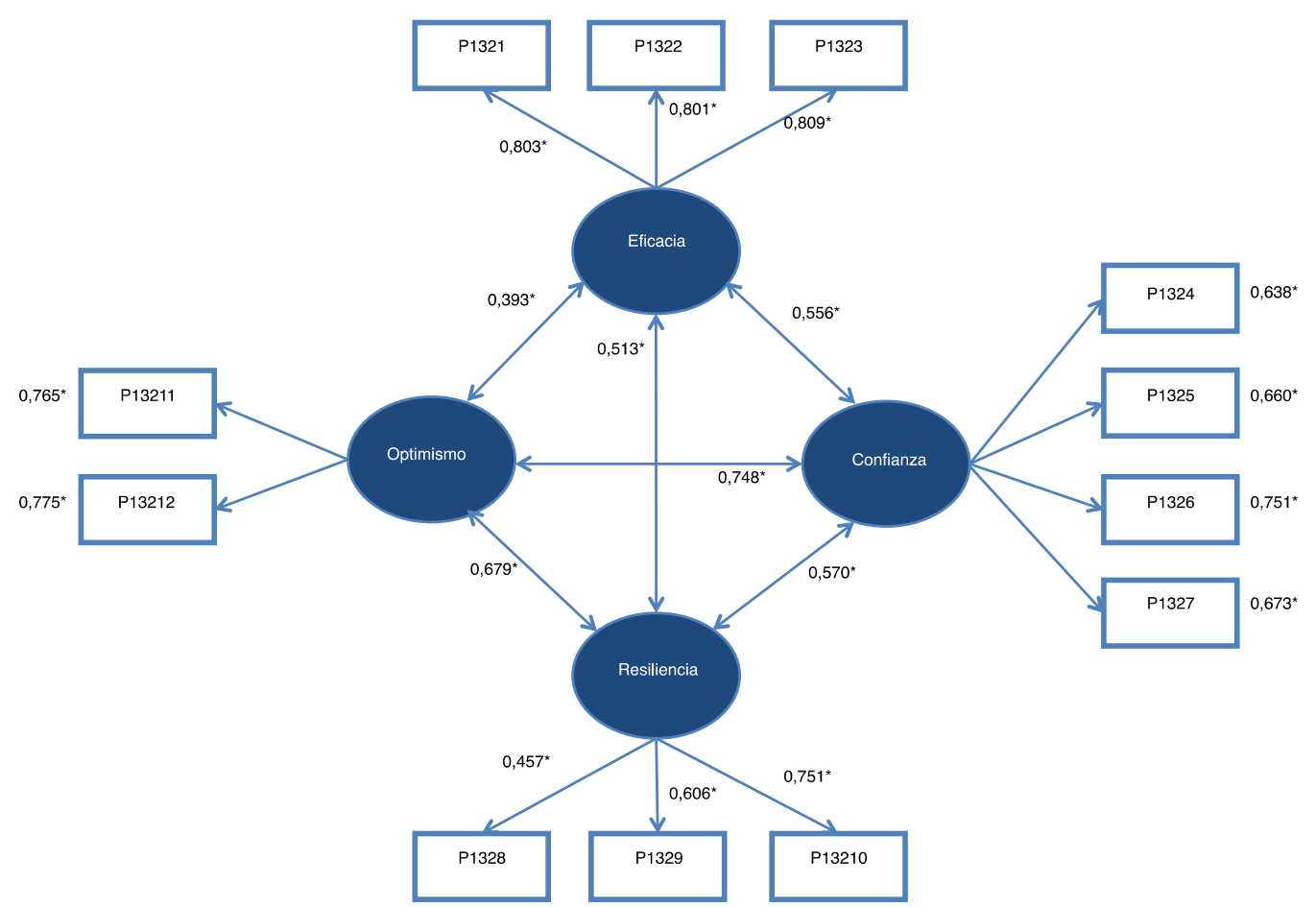

Figure 4. Confirmatory model of psychological capital, estimated from the DWLS method. ${ }^{*} p<.01$.

Regarding the final structural model (see Figure 5), it was chosen the DWLS method for the estimation, obtaining the following results of the goodness of fit indices: CFI $=0.996$; TLI $=0.995 ;$ RMSEA $=0.023(90 \%$ confidence interval with lower and upper limit of 0 and 0.044 , respectively), and SRMR $=0.059$. Positive and significant regressions were found between transformational leadership with organiza- tional climate $(\beta=0.523 ; p<.01)$, and organizational climate with psychological capital $(\beta=0.256 ; p<.01)$. Cronbach's alpha coefficient, calculated from the final model, was 0.844 . The above indices indicate a good fit of the data of the proposed theoretical model. All estimates, both in the final model and in the confirmatory analysis of each of the variables, were statistically significant at $p<.01$.

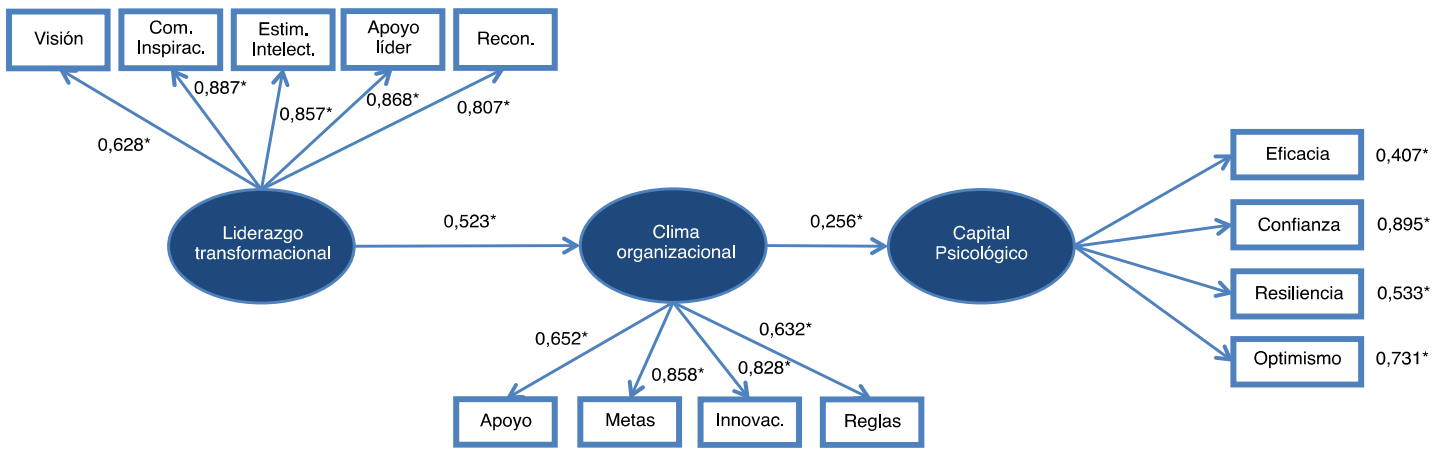

Figure 5. Final model, calculated using structural equations with DWLS estimation method. Positive and significant regression between transformational leadership and organizational climate of 0.523 and positive and significant regression between organizational climate and psychological capital of $0.256 . * p<$ .01 .

\section{Conclusions}

The aim of this study is to test the influence of management practices on organizational climate and employees' psychological capital. Starting with our first hypothesis of study, this has been validated obtaining a positive and significant relationship between transformational leadership and organizational climate. The results of our research are consistent with the most current research on this relationship (i.e., Zohar \& Tenne-Gazit, 2008). In this way, we refer to the importance 
of developing leaders capable of directing people towards a shared purpose and achieving the commitment, as it will lead to the strengthening of a positive organizational climate. This, compared with transactional leaders, must assume the reference point in organizations to achieve a positive psychological capital among their workers, like other affective variables and positive attitudes, such as job satisfaction or motivation. Validated in our study a relationship between transformational leadership and organizational climate, it becomes clear for the organization to train transformational leaders and to propose measures for individuals, work teams and organization to strengthen a positive climate. Among other measures, we can highlight the need to promote institutional loyalty, generate enthusiasm among the members of the organization with the aim of reaching a collective identity of all workers or that they actively participate by forming working teams to establish dynamics on continuous improvement processes of the administration and, at the same time, to check the effectiveness of the participation system.

The second hypothesis of study has also been validated with a well-fitting model, obtaining a positive and significant relationship between organizational climate and psychological capital. We proposed a differential approach connecting organizational climate and psychological capital, suggesting in our research a direct relationship between the two variables instead of posing psychological capital as a mediating variable of the relationship between climate and organizational results (see, for example, the aforementioned article by Suifan, 2016). The data obtained in our study supports our hypothesis, based on the model by Kopelman, Brief \& Guzzo (1990). Being the psychological capital a variable of recent study (Luthans \& Youssef, 2004), further research is needed to support either approach and to support integrating theories with the variables under study. Direct practical implications derived from this finding also express the need to foster a positive organizational climate on employees. Although we obtained a regression of 0.256 between organizational climate and psychological capital, a direct relationship can be attributed as they show a statistically significant result with the well-fitted model, according to the goodness of fit indices reviewed.

\section{References}

Bass, B. M. (1985). Leadership: Good, better, best. Organizational Dynamics, 13, 26-40.

Bass, B. M. \& Avolio, B. J. (2000). MLQ Multifactor Leadership Questionnaire Technical Report. Redwood City: Mindgarden.

Boada i Grau, J., De Diego Vallejo, R. \& Agulló, E. (2004). El burnout y las manifestaciones psicosomáticas como consecuentes del clima organizacional y de la motivación laboral. Psicothema, 16, 125-131.

Bowen, D. E. \& Ostroff, C. (2004). Understanding HRM-firm performance linkages: the role of the "strength" of the HRM system. Academy of Management Review, 29, 203-221.

Carr, J. Z., Schmidt, A. M., Ford, J. K. \& DeShon, R. P. (2003). Climate perceptions matter: A meta-analytical path analysis relating molar climate, cognitive and affective states, and individual level work outcomes. Journal of Applied Psychology, 88, 605-619.
With both study hypotheses accepted, our theoretical proposal has been statistically validated. In this proposal, the transformational leadership variable is positioned as antecedent of organizational climate; and psychological capital, as resulting therefrom. The contribution of our study was to strengthen the importance of transformational leadership as a new management style; its impact on organizational climate; and how the latter is a catalyst for psychological capital of administration employees. Therefore, the benefit to the employees of this public Administration lies in making a diagnosis of labor welfare through the relationships between the variables under study and how to improve it.

Despite the contributions of this paper, it is important to consider different limitations of statistical analysis, participants and results. Regarding statistical analysis, we are aware of the fact that if a model gets a good fit with a sample, it does not eliminate the possibility of others alternative theoretical models that can adjust well to the data collected. The relevance of statistical analysis conducted in this study gives way to further research in order to reaffirm the validity of the relationship of variables proposed. Inferences should not be regarded as definitive as no casual relationships have been studied. Our research has been conducted within the framework of the model of Kopelman, Brief \& Guzzo (1990), which supports the results obtained in the present study. With respect to the sample, we have been able to show the validity of the model when collecting variables of more recent studies on public employees, but we do not have data in this research that support other kinds of organizations. As a last limitation, regarding the capacity of generalization of the results, research using structural equations can only be generalized to that sample population.

Concerning future research, a comparative study of the theoretical model could be an object of interest reviewed in other than public administration. On the other hand, a study with transcultural participants should be introduced. With respect to other proposals of statistical analysis, if we performed a multilevel analysis, we could test the relationship among individuals, work groups and the organization with its formal leader. Similarly, a longitudinal study would allow continuous evaluation of changes in the organization, data which have not been collected in this study.

Chou, C. P., Bentler, P. M. \& Satorra, A. (1991). Scaled test statistics and robust standard errors for non-normal data in covariance structure analysis: a Monte Carlo study. British Journal of Mathematical and Statistical Psychology, 44, 347-357.

Cronbach, L. J. (1951). Coefficient alpha and the internal structure of tests. Psychometrika, 22, 297-334.

Feng Jing, F., Avery, G. C. \& Bergsteiner, H. (2011). Organizational climate and performance in retail pharmacies. Leadership \& Organization Development Journal, 32, 224-242.

Fox, J. (2006). Structural Equation Modeling with the sem package in R Structural Equation Modeling, 13, 465-486.

Hox, J. J., Maas, C. J. M. \& Brinkhuis, M. J. S. (2010). The effect of estimation method and sample size in multilevel structural equation modeling. Statistica Neerlandica, 64, 157-170. 
Hu, L. T. \& Bentler, P. M. (1999). Cutoff criteria for fit indexes in covariance structure analysis: conventional criteria versus new alternatives. Structural Equation Modeling, 6, 1-55.

Jöreskog, K. G. \& Sörbom, D. (1996). LISREL 8: User's Reference Guide. Chicago: Scientific Software International.

Kopelman, R. E., Brief, A. P. \& Guzzo, R. A. (1990). The role of climate and culture in productivity. En B. Schneider (Ed.), Organizational climate and culture (pp. 282-318). San Francisco: Jossey-Bass.

Kozlowski, S. W. J. \& Klein, K. J. (2000). A multilevel approach to theory and research in organizations. En K. J. Klein y S. W. J. Kozlowski (Eds.), Multilevel theory, research, and methods in organizations. San Francisco: Jossey-Bass.

Lewin, K., Lippitt, R. \& White, R. K. (1939). Patterns of aggressive behavior in experimentally created social climates. The Journal of Social Psychology, 10, 271-299.

Luthans, F., Luthans, K. W. \& Luthans, B. C. (2004). Positive psychological capital: Beyond human and social capital. Business Horizons, 47, 45-50.

Luthans, F. \& Youssef, C. M. (2004). Human, Social, and Now Positive Psychological Capital Management: Investing in People for Competitive Advantage. Organizational Dynamics, 33, 143-160.

Luthans, F., Avolio, B. J., Avey, J. B. \& Norman, S. M. (2007). Positive psychological capital: measurement and relationship with performance and satisfaction. Personnel Psychology, 60, 547-572.

Luthans, F., Avey, J. B., Avolio, B. J. \& Peterson, S. J. (2010). The development and resulting performance impact of positive psychological capital. Human Resource Development Quarterly, 21, 41-67.

Luthans, F., Norman, S. M., Avolio, B. J. \& Avey, J. B. (2008). The mediating role of psychological capital in the supportive organizational climate - employee performance relationship. Journal of Organizational Behavior, 29, 219-238.

Mañas, M. A., González-Romá, V. \& Peiró, J. M. (1999). El clima de los equipos de trabajo: determinantes y consecuencias. Almería: Servicio de publicaciones Universidad de Almería.

Ostroff, C. \& Bowen, D. E. (2000). Moving HR to a higher level: HR practices and organizational effectiveness. En K. J. Klein y S. W. J. Kozlowski (Eds.), Multilevel theory, research, and methods in organizations (pp. 211-266). San Francisco: Jossey-Bass.

PwC Spain (2012). ¿En qué hay que transformar la Administración Pública española? Disponible en: http://www.pwc.es/es_ES/es/publicaciones/sector -publico/assets/transformar-administracion-publica-esp.pdf

Qadeer, F. \& Jaffery, H. (2014). Mediation of Psychological Capital Between Organizational Climate and Organizational Citizenship Behavior. Pakistan Journal of Commerce and Social Sciences, 8, 453-470.

Quinn, R. E. \& Rohrbraugh, J. (1983). A spatial model of effectiveness criteria: Towards a competing values approach to organizational analysis. Management Science, 29, 363-377.
Rafferty, A. E. \& Griffin, M. A. (2004). Dimensions of transformational leadership: Conceptual and empirical extensions. The Leadership Quarterly, 15, 329-354.

Rosseel, Y. (2012a). Lavaan: an R package for structural equation modeling. Journal of Statistical Software, 48, 1-36.

Rosseel, Y. (2012b). Package 'lavaan'. Disponible en: http://cran.rproject.org/web/packages/lavaan/lavaan.pdf

Rosseel, Y. (2014). The lavaan tutorial. Disponible en: http:/ / lavaan.ugent.be/tutorial/tutorial.pdf

Salanova, M. (2008). Organizaciones saludables: una perspectiva desde la psicología positiva. En C. Vázquez, y G. Hervás (Ed.), Psicología Positiva Aplicada (pp. 403-428). Bilbao: Desclée de Brouwer.

Salgado, J. F., Remeseiro, C. \& Iglesias, M. (1996). Clima laboral y satisfacción laboral en una PYME. Psicothema, 8, 329-335.

Schneider, B. (2000). The psychological life of organizations. En N. M. Ashkanasy y C. P. M. Wilderom (Eds.), Handbook of organizational culture and climate (pp. 17-21). Thousand Oaks: Sage.

Schneider, B., Ehrhart, M. G. \& Macey, W. H. (2013). Organizational Climate and Culture. Annual Review of Psychology, 64, 361-388.

Schulte, M., Ostroff, C., Schmulyian, S. \& Kinicki, A. (2009). Organizational Climate Configurations: Relationships to Collective Attitudes, Customer Satisfaction, and Financial Performance. Journal of Applied Psychology, 94, 618-634.

Suifan, T. S. (2016). The impact of Organizational Climate and Psychological Capital on Organizational Citizenship Behavior. International Journal of Business and Management, 11, 224-230.

Syrek, C. J., Apostel, E. \& Antoni, C. H. (2013). Stress in Highly Demanding IT Jobs: Transformational Leadership Moderates the Impact of Time Pressure on Exhaustion and Work-Life Balance. Journal of Occupational Health Psychology, 18, 252-261.

Van Muijen, J., Koopman, P., De Witte, K., De Cock, G., Susanj, Z., Lemoine, C., Bourantas, D., Papalexandris, N., Branyicski, I., Spaltro, E., Jesuino, J., Gonzalves das Neves, J., Pitariu, H., Konrad, E., Peiró, J. M., González-Roma, V. \& Turnipseed, D. (1999). Organizational culture: The Focus Questionnaire. European Journal of Work and Organizational Psychology, 8, 551-568.

Walumbwa, F. O., Peterson, S. J., Avolio, B. J. \& Hartnell, C. A. (2010). An investigation between the relationships among leader and follower psychological capital, service climate and job performance. Personnel Psychology, 63, 937-963.

Zohar, D. \& Tenne-Gazit, O. (2008). Transformational Leadership and Group Interaction as Climate Antecedents: A Social Network Analysis, Journal of Applied Psychology, 93, 744-757.

(Article received: 13-07-2015; revised: 22-02-2016; accepted: 13-04-2016) 